\title{
Kinetics and Mechanism of the Addition of Benzylamines to $\alpha$-Thiophenyl- $\beta$-phenylacrylonitriles in Acetonitrile
}

\author{
Myoung Hwa Ku, Hyuck Keun Oh, and Seokbeom Ko* \\ Department of Chemistry: Research Institute of Basic Science and Research Institute of Phisics and Chemistrv: \\ Chonbuk National Liniversity Jeonit 561-756, Korea. "E-mail ohkeuna chonbuk ac.kr \\ Institute of Science Edtcation, Division of Science Education, Chonbuk National Lniversity, Jeonju 561-756, Korea \\ Received April 5, 2007
}

Key Words : Nucleophilic addition reaction. Single-step process. Cross-interaction constant. Kinetic isotope effects. Four-center cyclic transition state

Addition of anines $\left(\mathrm{XRNH}_{2}\right)$ to olefins $\left(\mathrm{YC}_{6} \mathrm{H}_{4} \mathrm{CH}=\right.$ $\left(Z Z Z^{\prime}\right)$ is known to proceed in acetonitrile by concerted formation of the $\mathrm{C}_{\beta}-\mathrm{N}$ and $\mathrm{C}_{\alpha x}-\mathrm{H}$ bonds in a single-step process leading to a neutral product. ${ }^{1} \mathrm{I}$. This is. however. quite in contrast to the mechanism in aqueous solution. which occurs through a zwitterionic intermediate. II $\left(\mathrm{T}^{ \pm}\right)$. with inbalanced transition states (TSs) in which the development of resonance into the activating (electronacceptor) group (Z.Z') lags behind charge transfer of bond formation. ${ }^{2}$ The rates of amine additions in acetonirile are in general much slower than in aqueous solution $\left(k_{\Sigma}(\mathrm{aq})=10^{4} \times\right.$ $k_{2}(\mathrm{MeCN})$ ), but the relative order depending on the $Z, Z^{\prime}$ group was found to remain the same. ${ }^{1}$ The mechanistic difference found between amine additions to the activated olefins in aqueous and acetonitrile solutions has been attributed to (i) weak solvation by $\mathrm{MeCN}$ to stabilize the carbanion in the putative intermediate $\left(\mathrm{T}^{ \pm}\right)$. and (ii) hydrogen bonding to negative charge localized on $\mathrm{C}_{\alpha \alpha}$ in the TS due partly to the well known "imbalance", which causes a lag in charge delocalization into the activating groups $\left(\mathrm{Z}, \mathrm{Z}^{\prime}\right)$ behind $\mathrm{C} \cdot \mathrm{N}$ bond formation ${ }^{{ }^{2}}$ Another interesting point is that the sign and magnitude $\left(\rho_{\mathrm{XY}}=-0.6\right.$ to -0.8$)$ of the cross-interaction constant $(\mathrm{ClC})$ [ $\mathrm{r}_{\mathrm{XY}}$ in eq. $(\mathrm{l})^{3}$ where $\mathrm{X}$ and $\mathrm{Y}$ are substituents in the nucleophile and substrate for the one-step amine additions] are in general agreement with those for the bond formation in the concerted nucleophilic substitution $\left(\mathrm{S}_{*} 2\right)$ reactions. $^{3}$

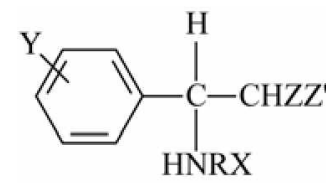

I

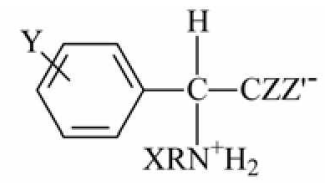

II $\left(\mathbf{T}^{\mathbb{t}}\right)$

$$
\begin{aligned}
& \log \left(k_{\mathrm{X}} / k_{\mathrm{HH}}\right)=\rho_{\mathrm{X}} \sigma_{\mathrm{X}}+\rho_{\mathrm{Y}} \sigma_{\mathrm{Y}}+\rho_{\mathrm{XY}} \sigma_{\mathrm{X}} \sigma_{\mathrm{Y}} \\
& \rho_{\mathrm{XY}}=\partial \rho_{\mathrm{Z}} / \partial \sigma_{\mathrm{Y}}=\partial \rho_{\mathrm{Y}} / \partial \sigma_{\mathrm{Z}}
\end{aligned}
$$

In this work we carried out kinetic studies of the benzylamine $\left(\mathrm{XC}_{6} \mathrm{H}_{4} \mathrm{CH}_{2} \mathrm{NH}_{2}\right)$ additions to $\alpha$-thiopheny $1-\beta$-phenylacrylonitriles (TPA: $Z Z^{\prime}=\mathrm{CN}, \mathrm{C}_{4} \mathrm{H}_{3} \mathrm{~S}$ ) in acetonitrile at 25.0. eq. (2).

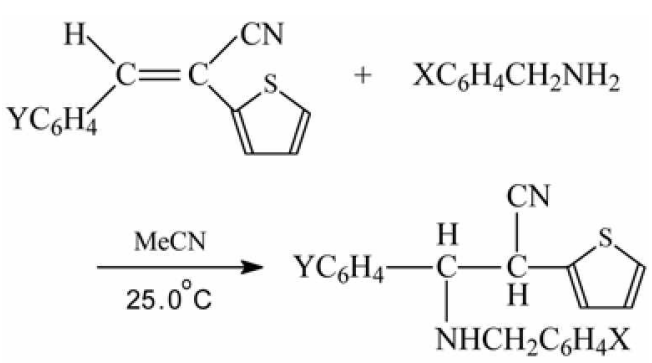

We aim to further explore the mechanistic differences between amine additions to olefin in aqueous and in acetonitrile solution. We are also interested in the effects of the activating groups, Z.Z'. on the mechanism of the amine addition in $\mathrm{MeCN}$ by examining closely the trends of changes in the isotope effects. $k_{\mathrm{H}} / k_{\mathrm{L}}$, determined using the deuterated benzy lamine nucleophiles $\left(\mathrm{XC}_{6} \mathrm{H}_{2} \mathrm{CH}_{2} \mathrm{ND}_{2}\right)$.

\section{Results and Discussion}

The reactions investigated in the present work obeyed a simple kinetic law given by eqs. (3) and (4) where $k_{2}$ is the second-order rate constant for the benzylamine (BA) addition to the substrate (S).

$$
\begin{gathered}
-\mathrm{d}[\mathrm{S}] / \mathrm{dt}=k_{\mathrm{vts}}[\mathrm{S}] \\
k_{\mathrm{ohs}}=k_{-}[\mathrm{BA}]
\end{gathered}
$$

In contrast to the benzylamine catalysis observed in the additions to $\beta$-nitrostyrene (NS). ${ }^{\text {la }}$ no catalysis was detected by a second $\mathrm{BA}$ molecule in the present studies. Plots of $k_{\mathrm{cbs}}$ against $[\mathrm{BA}]$ were linear with a c $a$. 10-fold increase in $[\mathrm{BA}]$. The $k_{2}$ values obtained from the slopes of these plots are summarized in Tables 1 .

The Hammett $\rho_{\mathrm{X}}$ and $\rho_{\mathrm{Y}}$ values are also shown in the tables together with the cross-interaction constants. $\rho_{\mathrm{XY}}$ [eq. (1)]. Comparison of the rates with those in aqueous solution ${ }^{4}$ shows that the rate constants in acetonitrile are lower by more than $10^{2}$-fold as we found for other substrates. e.g. benzylidenemalononitrile $(\mathrm{BMN}){ }^{\mathrm{lt}}$ 2-benzylideneindan1.3-dione (BID) ${ }^{\mathrm{lc}}$ and nitrostyrene (NS) ${ }^{\mathrm{la}}$ and $\beta$-cyano-4nitrostilbenes (CNS) ${ }^{\text {le }}$ We have collected reactivity parameters for various activating groups. $Z, Z$ '. in Table 2. An essential difference between the reactivity in aqueous solution and that in acetonitrile solution is that the fonmer 
Table 1. The Second Order Rate Constants, $k_{2} \times 10^{3} \mathrm{dm}^{3} \mathrm{~mol}^{-1} \mathrm{~s}^{-1}$ for the Addition Reactions of $\alpha$-thiophenyl- $\beta$-phenylacylonitriles with $\mathrm{X}$-Benzylanines in Acetonitrile at $25.0^{\circ} \mathrm{C}$

\begin{tabular}{|c|c|c|c|c|c|}
\hline \multirow{2}{*}{$\mathrm{X}$} & \multicolumn{5}{|c|}{$\mathrm{Y}$} \\
\hline & $p$-OMe & $p$-Me & $\mathrm{H}$ & $p-\mathrm{Br}$ & $\rho_{i}{ }^{\sigma}$ \\
\hline \multirow[t]{3}{*}{$p$-OMe } & 7.54 & 9.55 & 13.9 & 24.1 & $1.01 \pm 0.01$ \\
\hline & $4.02^{6}$ & & & 13.4 & \\
\hline & $2.17^{\circ}$ & & & 7.37 & \\
\hline$p$-Me & 7.02 & 8.51 & 12.0 & 19.9 & $0.91 \pm 0.01$ \\
\hline $\mathrm{H}$ & 6.03 & 7.08 & 10.2 & 160 & $0.86 \pm 0.01$ \\
\hline \multirow[t]{3}{*}{$p-\mathrm{Cl}$} & 5.01 & 5.98 & 8.02 & 12.4 & $0.78 \pm 0.01$ \\
\hline & 2.71 & & & 6.82 & \\
\hline & 1.44 & & & 3.68 & \\
\hline$n-\mathrm{Cl}$ & 1.56 & 5.00 & 6.66 & 9.75 & $0.68 \pm 0.01$ \\
\hline \multirow[t]{2}{*}{$\alpha^{l l}$} & -0.35 & -0.42 & -0.48 & -0.59 & \\
\hline & $( \pm 0.01)$ & $( \pm 0.01)$ & $( \pm 0.01)$ & $( \pm 0.02)$ & $\rho \mathrm{XY}^{*}=-0.45$ \\
\hline \multirow[t]{2}{*}{$\beta^{+}$} & 0.36 & 0.43 & 0.49 & 0.59 & $( \pm 0.04)$ \\
\hline & $( \pm 0.01)$ & $( \pm 0.01)$ & $( \pm 0.01)$ & $( \pm 0.02)$ & \\
\hline
\end{tabular}

"The $\sigma$ falues were taken from C. Hansch. A. Leo. and R. W. Taft. Chem. Rev. 1991. 91. 165. Correlation coefficients were better than $0.999 \mathrm{in}$ all cases. "At $15.0^{\circ} \mathrm{C}$. 'At 5.0 $0^{\circ} \mathrm{C}$. "The source of $s$ is the same as for footnote a. Correlation coefficients were better than $0.997 \mathrm{in}$ all cases. ${ }^{\circ}$ Correlation coefticients was 0.998 . 'The $\mathrm{pKa}$ values were taken from $\mathrm{A}$. Fischer. W. J. Galloway and J. Vaughan. J. Chem. Soc. 1964. 3588 Correlation coefficients were better than 0.995 in all cases. pKa $=9.67$ was used for $\mathrm{X}=p-\mathrm{CH}_{3} \mathrm{O}$. (reference H. K. Ol. J. Y. Lee, and I. Lee. $B$ whl. korean Chem. Soc. 1998. 19. 1198 ).

increases with the (polar) electron-withdrawing power (normal substituent constant $\sigma$ ) of the activating groups. Z.Z', (8th colunn in Table 2), whereas the latter depends on the through conjugative electron-withdrawing strength $\left(\sigma^{-}\right)^{-5}$ of the Z.Z' groups. For example in aqueous solution the intrinsic rate constant $\left(\log k_{i}\right)$. which represents a pure kinetic rate under thermoneutral conditions. "increases in the order NS $<\mathrm{BID}<\mathrm{CNS}<\mathrm{BMN}$. In constrast the rates in acetonirile are in the order $\mathrm{CNS}<\mathrm{TPA}<\mathrm{NS}<\mathrm{BID}$ BMN. which is roughly the order of the direct resonance effect. $\Sigma \sigma^{-}$. Note that we summed the substituent constants of $Z, Z$ '. and for BID this summation procedure may not be correct. especially for the direct resonance constants. So the exact correspondence of the reactivity with $\Sigma \sigma^{-}$camot be expected. but it is certain that the reactivities of BMN and BID are larger than those of the rest: NS. TPA and CNS ${ }^{\circ}$ Previous works indicate that there is steric inhibition of resonance for the $\alpha$-thiophenyl and phenyl rings in TPA and CNS so that the resonance effect of the $\alpha$-ring in these compounds is nonexistent. Eliminating the resonance effect of the $\alpha$-ring in these compounds changes the $\Sigma \sigma^{-}$values in the order CNS $<$ TPA $<$ NS as shown in the parentheses under the $\Sigma \sigma^{-}$columns in Table 2 . Thus if we take into account the approximate nature of the $\Sigma \sigma^{-}$value for BID, the rates in acetonitrile increase in the order being $\mathrm{CNS}<$ $\mathrm{CPA}<\mathrm{NS}<\mathrm{BID}<\mathrm{BMN}$.

The rates in aqueous solution are dependent on the polar electron-withdrawing effect $(\sigma)$ of $Z . Z$ ', while those in acetonitrile are determined by the direct resonance electronwithdrawing strength of the activating groups $\left(\sigma^{-}\right), Z . Z$ '. This difference is of course originated by the difference in the amine addition mechanisms in the two different media. It has been well established that the amine addition reactions of activated olefins in aqueous solution proceed by the initial rate-limiting addition of the amine to form a zwitterionic intermediate. $\mathrm{T}^{ \pm}$, which is deprotonated to an anionic intermediate $\left(\mathrm{T}^{-}\right)$in a later fast step and then on a longer time scale $\mathrm{T}^{-}$eventually decomposes [eq. (5)]. ${ }^{2}$ In the rate-

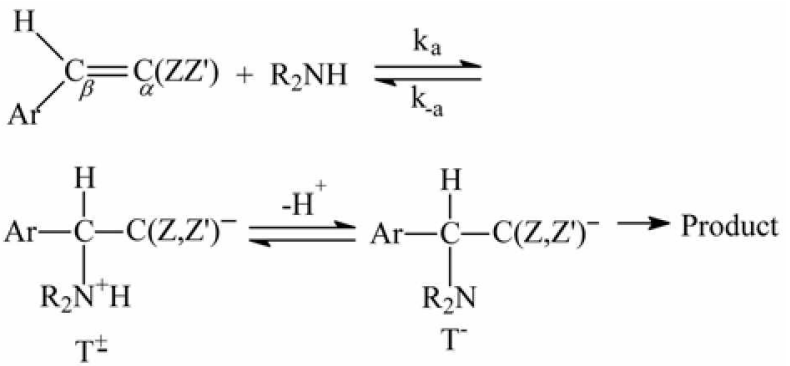

limiting addition step, $k_{\mathrm{a}}$, the positive charge on $\mathrm{C}_{\beta}$ is important. which is determined by the electron-withdrawing polar effect of $Z, Z$ '. The development of negative charge on $Z, Z$ ' lags behind bond making of the $N \cdots C_{\beta}$ bond in water to some extent depending on the $Z, Z$ ' groups.' Thus the ease of the initial attack by anines on $C_{\beta}$ and hence the polar electron-withdrawing effect of $Z, Z^{\prime}$ is the rate determining factor for the reaction in aqueous solution as evidenced by the rate sequence of the intrinsic rate constant with $\Sigma \sigma$ in Table 2. In contrast. however, the same reactions in a dipolar aprotic solvent. acetonitrile, proceed in a single step by concurrent fonmation of $\mathrm{N} \cdots \mathrm{C}_{\beta}$ and $\mathrm{H} \cdots \mathrm{C}_{\mathrm{a}}$ bonds to a saturated product. ${ }^{3}$ In this concerted addition in acetonitrile there is no transition state (TS) imbalance due to the lag in the negative charge delocalization within the $Z Z^{\prime}$ groups. and the direct resonance, or through conjugation. of the

Table 2. Comparisons of Reactivity Parameter for the Addition Reaction, $\mathrm{YC}_{0} \mathrm{H}_{4} \mathrm{CH}=\mathrm{CZZ}+\mathrm{XC}_{6} \mathrm{H}_{4} \mathrm{CH}_{2} \mathrm{NH}_{2}$, in $\mathrm{Acetonitrile}$ at 25.0 " $\mathrm{C}$

\begin{tabular}{|c|c|c|c|c|c|c|c|c|}
\hline Entry & $Z, Z^{\prime}$ & $k_{2}^{a} / \mathrm{M}^{-1} \mathrm{~s}^{-1}$ & $\log k_{0}^{b}$ & $\rho \mathrm{X}^{2}$ & $\rho^{c}$ & $\rho \mathrm{Nu}^{i i}$ & $\Sigma \sigma$ & $\Sigma \sigma^{-f}$ \\
\hline $1(\mathrm{BMN})^{\mathrm{E}}$ & $\mathrm{CN}, \mathrm{CN}$ & 1.48 & $4.94^{x}$ & -1.62 & -0.55 & -0.31 & 1.32 & 2.00 \\
\hline $2(\mathrm{BID})^{h}$ & $(\mathrm{CO})_{2} \mathrm{C}_{6} \mathrm{H}_{4}$ & 1.48 & 4.20 & -1.10 & 0.41 & -0.33 & 0.83 & 2.08 \\
\hline $3(\mathrm{NS})^{1}$ & $\mathrm{NO}_{2}, \mathrm{H}$ & $2.63 \times 10^{-2}=$ & 2.55 & -1.22 & 1.73 & -0.40 & 0.78 & 1.27 \\
\hline $4(\mathrm{TPA})$ & $\mathrm{CN}, \mathrm{C}_{+} \mathrm{H}_{2} \mathrm{~S}$ & $1.02 \times 10^{-2}=$ & - & -0.48 & 0.86 & -0.45 & 0.71 & 1.19 \\
\hline $5(\mathrm{CNS})^{k}$ & $\mathrm{CN}, p-\mathrm{NO}_{2} \mathrm{C}_{5} \mathrm{H}_{4}$ & $1.26 \times 10^{-3}$ & 3.35 & -1.15 & 1.10 & -0.67 & 0.92 & 1.00 \\
\hline
\end{tabular}

"For $\mathrm{X}=\mathrm{Y}=\mathrm{H}$ at $25.0^{\circ} \mathrm{C}$ unless otherwise noted in parentheses. "Estrapolated value. "Intrinsic rate constants, $k$, for carbanion fonming reactions $\left(k_{\mathrm{a}}\right.$ in

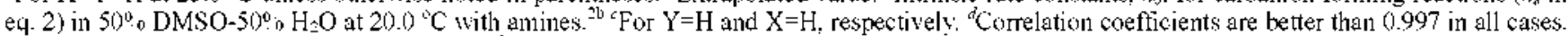

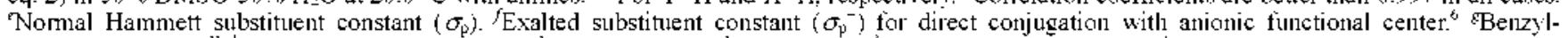
idenemalononitrile. ${ }^{\text {dh }}$ Benzylidene-1.3-indandione. ${ }^{14} / \beta$-Nitrostyrene. ${ }^{1 / 3}$ This work ${ }^{k} \beta$-Cyano- $\beta$-t-nitrostilbene. ${ }^{\text {le }}$ 
incipient anionic charge on $C_{\beta}$ toward the $Z, Z^{\prime}$ groups is the most important TS stabilization which deternines the reacitivity. Thus for the reactions in acetonitrile the reacitivity depends primarily on the resonance electron-withdrawing effect of the $Z . Z^{\prime}$ groups. Since in such resonance stabilized TS the two large activating groups. e.g. $Z, Z^{\prime}=\mathrm{CN}$ and thiophenyl groups, interfere sterically. ${ }^{6}$ the resonance effect of the thiophenyl group becomes negligible since steric hindrance prevents $\pi$-overlap with the thiophenyl group. This is why the two compounds. TPA $\left(Z, Z^{\prime}=C N\right.$. $\left.\mathrm{C}_{4} \mathrm{H}_{3} \mathrm{~S}\right)$ and $\mathrm{NS}\left(\mathrm{Z}, \mathrm{Z}^{\prime}=\mathrm{NO}_{2}, \mathrm{H}\right)$. have almost the same reactivity (Table 2). i.e., the resonance effect of the $\mathrm{C}_{4} \mathrm{H}_{3} \mathrm{~S}$ group becomes nearly zero.

We note in Table 2 that the sign of $\rho_{\mathrm{XY}}$ is negative in all cases as expected from a bond formation process, ${ }^{3}$ and the magnitude of $\rho_{\mathrm{XY}}$ is larger for TPA than for other substrates ${ }^{1}$ (entries 1-3) suggesting a stronger interaction between substituents in the approaching nucleophile $(X)$ and in the ring $(\mathrm{Y})$ through the reaction center. $\mathrm{C}_{\beta}$. This could be due (i) to the larger negative charge on $C_{\beta}$ as a result of the weaker resonance electron-withdrawing effect from the $Z, Z^{\prime}$ groups and (ii) to the greater degree of bond making with closer $\mathrm{N}$ and $\mathrm{C}_{\beta}$ in the $\mathrm{TS}$.

The kinetic isotope effects. $k_{\mathrm{H}} / k_{\mathrm{D}}$ (Table 3 ). involving deuterated benzylamine nucleophiles ${ }^{7}\left(\mathrm{XC}_{6} \mathrm{H}_{4} \mathrm{CH}_{2} \mathrm{ND}_{2}\right)$ are greater than unity, $k_{\mathrm{H}} / k_{\mathrm{D}}=1.7-2.2$ suggesting a possibility of forming hydrogen-bonded four-center type TS, III as often been proposed for similar reactions. ${ }^{8}$ The Hydrogen bonding of N-H proton toward a cyano nitrogen (IV) may be a possibility. but involves a too long hydrogen-bond since the lone pair on $\mathrm{N}$ of benzylamine approaches alnost vertically from above (or below) the molecular plane of TPA to the $\mathrm{C}_{\sigma}$ $\mathrm{C}_{\beta} \pi$-bond. The relatively smaller values of $k_{\mathrm{H}} / k_{\mathrm{D}}$ (1.74-
III

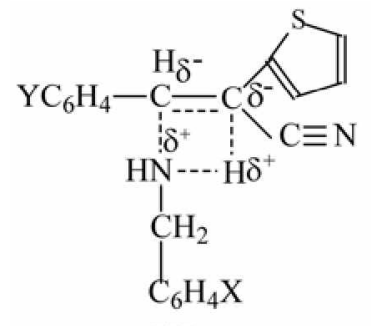

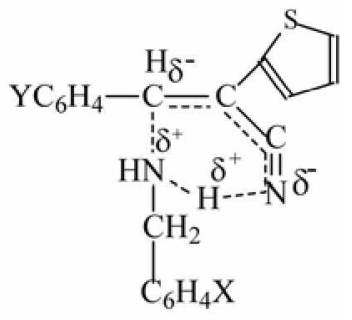

IV
Table 3. Kinetic Isotope Effects on the Second-Order rate constants $\left(k_{2}\right)$ for the Reactions of $\alpha$-thiophenyl- $\beta$-phenylacylonitriles with Deuterated X-Benzylamines in Acetonitrile at $25.0^{\circ} \mathrm{C}$

\begin{tabular}{ccccc}
\hline $\mathrm{X}$ & $\mathrm{Y}$ & $\begin{array}{c}k_{\mathrm{H}} \times 10^{3} \\
\left(\mathrm{M}^{-1} \mathrm{~S}^{-1}\right)\end{array}$ & $\begin{array}{c}k_{\mathrm{D}} \times 10^{3} \\
\left(\mathrm{M}^{-1} \mathrm{~s}^{-1}\right)\end{array}$ & $k_{\mathrm{H}} / k_{\mathrm{D}}$ \\
\hline$p-\mathrm{OMe}$ & $p-\mathrm{Me}$ & $7.54( \pm 0.08)$ & $3.62( \pm 0.05)$ & $2.08 \pm 0.03^{a}$ \\
$p-\mathrm{OMe}$ & $\mathrm{H}$ & $9.55( \pm 0.12)$ & $4.82( \pm 0.06)$ & $1.98 \pm 0.03$ \\
$p-\mathrm{OMe}$ & $p-\mathrm{Cl}$ & $13.9( \pm 0.15)$ & $7.47( \pm 0.08)$ & $1.86 \pm 0.02$ \\
$P-\mathrm{OMe}$ & $p-\mathrm{BT}$ & $24.1( \pm 0.35)$ & $13.8( \pm 0.15)$ & $1.74 \pm 0.02$ \\
$p-\mathrm{Cl}$ & $p-\mathrm{Me}$ & $5.01( \pm 0.06)$ & $2.31( \pm 0.03)$ & $2.17 \pm 0.03$ \\
$p-\mathrm{Cl}$ & $\mathrm{H}$ & $5.98( \pm 0.07)$ & $2.90( \pm 0.04)$ & $2.06 \pm 0.02$ \\
$p-\mathrm{Cl}$ & $p-\mathrm{Cl}$ & $8.02( \pm 0.09)$ & $4.18( \pm 0.05)$ & $1.92 \pm 0.03$ \\
$p-\mathrm{Cl}$ & $p-\mathrm{Br}$ & $12.4( \pm 0.12)$ & $6.63( \pm 0.08)$ & $1.87 \pm 0.04$ \\
\hline
\end{tabular}

"Standard deviations.
2.17) than those corresponding values for the reactions of $\mathrm{NS}\left(k_{\mathrm{H}} / k_{\mathrm{D}}=2.30-3.08\right), \mathrm{BMN}\left(k_{\mathrm{H}} / k_{\mathrm{D}}=2.25-2.71\right)$, NSB $\left(k_{\mathrm{H}} /\right.$ $\left.k_{\mathrm{D}}=2.42-2.71\right)$ and CNS $\left(k_{\mathrm{H}} / k_{\mathrm{D}}=2.15-2.61\right)$ could be due to the lower degree of bond formation (smaller magnitude of $\rho_{\mathrm{S}}$ and $\left.\beta_{\mathrm{S}}\right)$ in the TS for TPA. Another interesting result is that the $k_{\mathrm{H}} / k_{\mathrm{D}}$ value for TPA increases with an electronacceptor $\mathrm{X}\left(\partial \sigma_{\mathrm{X}}>0\right)$ and with an electron-donor $\mathrm{Y}\left(\partial \sigma_{\mathrm{Y}}<\right.$ 0 ), which is exactly opposite to the trends found for NS. BMN, BID and CNS. for which the $k_{\mathrm{H}} / k_{\mathrm{D}}$, value decreases with an electron-acceptor $\mathrm{X}$ and an electron-donor $\mathrm{Y}^{2}$ This opposite trend may also be due to the looser TS with a lower degree of bond-making. In such a case. the greater negative charge on $\mathrm{C}_{x}$ (with an electron-donor $\mathrm{Y}$ ) and the greater acidity of $\mathrm{NH}$ proton (with an electron-acceptor $\mathrm{X}$ ) are important for the hydrogen bond bridge formation. This is in contrast to the tightly formed $\mathrm{C}_{\beta} \mathrm{N}$ bond for the NS. BMN and $\mathrm{CNC}$ for which the $k_{\mathrm{H}} / k_{\mathrm{D}}$ depends on the extent of bondmaking. i.e.. a greater degree of bond-making by an electron-donor $\mathrm{X}$ and an electron-acceptor $\mathrm{Y}$ leads to a stronger hydrogen bond (larger $k_{\mathrm{H}} / k_{\mathrm{D}}$ ) which varies more sensitively with substituents $\mathrm{X}$ and $\mathrm{Y}$. The overall size of the $k_{\mathrm{H}} / k_{\mathrm{D}}$ values ranging $1.7-2.2$ are smaller than those of the corresponding values for the substrates with weaker electron acceptor Z.Z' exhibiting slower addition rate, e.g. for entries 4 and 6 in Table 2 the $k_{\mathrm{H}} / k_{\mathrm{L}}$, values are larger ranging 2.2$3.1^{\text {la,e }}$

The activation parameters. $\Delta H^{*}$ and $\Delta S^{1 \neq}$ (Table 4), are quite similar to those for the corresponding reaction of other activated olefins in Table 2 in acetonitrile with low $\Delta H^{*}$ and large negative $\Delta S^{t \neq}$ values. These are consistent with the concurrent $\mathrm{N}-\mathrm{C}_{\beta}$ and $\mathrm{H}-\mathrm{C}_{\alpha}$ bond formation in the TS. III. Since exclusion repulsion energy in the $\mathrm{N}-\mathrm{C}_{\beta}$ bond making is partially offset by the bond energy of the partial bond fomed, and also by the $\mathrm{H}-\mathrm{C}_{z}$ bond formation. barrier to bond fomation in the rate deternining step should be low with little variation depending on $\mathrm{X}$ and/or $\mathrm{Y}$. This is because the higher barrier for a weaker nucleophile $\left(\delta \sigma_{\mathrm{x}}>\right.$ 0 ) is partially offset by a stronger acidity of the N-H proton in the H-bond fomation. The large negative entropy of activation is in line with four-centered constrained TS structure. III.

In summary. the addition of benzylamine (BA) to $\alpha$-thiophenyl- $\beta$-phenylacrylonitriles (TPA) take place in a single step in which the $\mathrm{C}_{\beta}-\mathrm{N}$ bond formation and proton transfer to $C_{\measuredangle}$ of TPA occur concurrently with a four-membered

Table 4. Activation Parameters" for the Reactions of $\alpha$-thiophenyl$\beta$ phenylacylonitriles with X-Benzylamines in Acetonitrile

\begin{tabular}{cccc}
\hline $\mathrm{X}$ & $\mathrm{Y}$ & $\Delta H^{*} / \mathrm{kcal} \mathrm{mol}^{-1}$ & $-\Delta S^{*} / \mathrm{cal} \mathrm{mol}^{-1} \mathrm{~K}^{-1}$ \\
\hline$p-\mathrm{OMe}$ & $p-\mathrm{OMe}$ & 9.7 & 36 \\
$p-\mathrm{OMe}$ & $p-\mathrm{Br}$ & 9.2 & 35 \\
$p-\mathrm{Cl}$ & $p-\mathrm{OMe}$ & 9.7 & 37 \\
$p-\mathrm{Cl}$ & $p-\mathrm{Br}$ & 9.3 & 36 \\
\hline
\end{tabular}

"Calculated by the Eyring equation. The maximum errors calculated $(b y$ the method of K. B. Wiberg. Pinsicol Orgonic Chentisty, Wiley. New York. 1964, o 378) are $\pm 0.9 \mathrm{kcal} \mathrm{mol} \mathrm{l}^{-1}$ and \pm 3 e.t. for $\Delta H^{x}$ and $\Delta S^{x}$. respectively. 
cyclic TS structure, III. The reaction center carbon. $\mathrm{C}_{\beta}$ becomes more negative $\left(\rho_{Y}>0\right)$ on going from the reactant to TS, but the negative charge development is stronger than that for the reactions of BID. The sign and magnitude of the cross-interaction constant, $\rho \mathrm{XY}$, is comparable to those for the normal bond fornation processes in the $\mathrm{S}_{\mathrm{N}} 2$ and addition reactions. The normal kinetic isotope effects, $k_{\mathrm{H}} / k_{\mathrm{D}}(>\mathrm{I})$. involving denterated benzylamine nucleophiles, are somewhat smaller than those corresponding values for the reaction of CNS due to the smaller extent of bond formation in the TS. The relatively low $\Delta H^{*}$ and large negative $\Delta S^{\mp}$ values are also consistent with the mechanism proposed.

\section{Experimental Section}

Materials. GR grade acetonitrile was used after three distillations. GR grade benzy lamine nucleophiles were used after recrystallization. 2-Thiopheneacetonitrile and benzaldehydes were also GR grade.

Preparartions of $\alpha$-Thiophenyl- $\beta$-phenylacrylonitriles. The $\alpha$-thiophenyl- $\beta$-phenylacylonitriles were prepared by the literature method of Schonne, Braye and Bruylants. ${ }^{11} \dot{A}$ solution of 2-thiopheneacetonitrile (10 minol) and benzaldehyde (10 mmol) in absolute ethanol was treated with a few drops of sodium ethoxide and refluxed for $3 \mathrm{~h}$. The solution was cooled, some of the ethanol was evaporated. and the dark-colored solid was removed by filteration to yield $(85 \%)$ of crude material. This was recrystallized from ethanol. The other substituted $\alpha$-thiophenyl- $\beta$-phenylacylonitriles were prepared in an analogous manner and recrystallized from ethanol. The substrates synthesized were confirmed by melting points and spetral analysis as follows.

4- $\mathrm{CH}_{3} \mathrm{OC}_{6} \mathrm{H}_{4} \mathbf{C H}=\mathbf{C}(\mathbf{C N}) \mathrm{C}_{4} \mathbf{S H}_{3}$ : m.p. $105-107^{\circ} \mathrm{C}$. $\hat{\lambda}_{\text {max }}$ $353 \mathrm{~nm} ; \mathrm{IR}(\mathrm{KBr}), 3025(\mathrm{C}-\mathrm{H}$, aromatic), $22 \mathrm{l} 3(\mathrm{C} \equiv \mathrm{N}), 1608$ $\left(\mathrm{C}=\mathrm{C}\right.$, alkene). $1586\left(\mathrm{C}=\mathrm{C}\right.$. aromatic): ${ }^{1} \mathrm{H}$ NMR $(400 \mathrm{MHz}$. $\left.\mathrm{CDCl}_{3}\right), 3.85\left(3 \mathrm{H} . \mathrm{s}, \mathrm{OCH}_{3}\right), 7.05(2 \mathrm{H}, \mathrm{d}$, thiophene), 7.20 ( $2 \mathrm{H}, \mathrm{m}$, aromatic). 7.30 (1H. s. alkene). 7.33 (2H. d. thiophene) $7.83\left(2 \mathrm{H} . \mathrm{d}\right.$ aromatic): ${ }^{13} \mathrm{C}$ NMR $(100.4 \mathrm{MHz}$ $\left.\mathrm{CDCl}_{3}\right), 161.3,139.5,130.9,130.7$. 127.9. 127.2. 126.4. 125.4. 114.4. 113.9. 103.2. 45.7.

${ }_{4}-\mathrm{CH}_{3} \mathrm{C}_{6} \mathrm{H}_{4} \mathrm{CH}=\mathrm{C}\left(\mathrm{CN}_{4} \mathrm{C}_{4} \mathrm{SH}_{3}\right.$ : m.p. $100-102^{\circ} \mathrm{C}$. $\lambda_{\text {max }} 340$ num: IR ( $\mathrm{KBr}), 3022(\mathrm{C}-\mathrm{H}$, aromatic), $2216(\mathrm{C} \equiv \mathrm{N}), 1606$ $\left(\mathrm{C}=\mathrm{C}\right.$. alkene). $1596\left(\mathrm{C}=\mathrm{C}\right.$. aromatic): ${ }^{1} \mathrm{H}$ NMR $(400 \mathrm{MHz}$. $\left.\mathrm{CDCl}_{3}\right), 2.35\left(3 \mathrm{H} . \mathrm{s}, \mathrm{CH}_{3}\right), 7.02(2 \mathrm{H}$. d, thiophene), $7.24(2 \mathrm{H}$, $\mathrm{m}$, aromatic), $7.28(1 \mathrm{H}, \mathrm{s}$, alkene), $7.32(2 \mathrm{H}, \mathrm{d}$, thiophene). $7.72\left(2 \mathrm{H}\right.$. d aromatic): ${ }^{13} \mathrm{C}$ NMR $\left(100.4 \mathrm{MHz}, \mathrm{CDCl}_{3}\right) .140 .9$, 139.5. 130.4, 139.5. 129.4, 129.1. 127.8, 126.7. 125.7, 116.9. 104.7

$\mathrm{C}_{6} \mathrm{H}_{5} \mathrm{CH}=\mathrm{C}(\mathrm{CN}) \mathrm{C}_{4} \mathrm{SH}_{3}:$ m.p. $80-82^{\circ} \mathrm{C} . \hat{\lambda}_{\max } 337 \mathrm{~nm} ; \mathrm{IR}$ $(\mathrm{KBr}) .3024(\mathrm{C} \cdot \mathrm{H}$. aronatic), $2214(\mathrm{C} \equiv \mathrm{N}) .1591(\mathrm{C}=\mathrm{C}$. alkene), $1595\left(\mathrm{C}=\mathrm{C}\right.$. aromatic): ${ }^{1} \mathrm{H} N \mathrm{NR}\left(400 \mathrm{MHz}, \mathrm{CDCl}_{3}\right)$, $7.08(2 \mathrm{H}, \mathrm{d}$, thiophene). $7.25(\mathrm{HH}, \mathrm{s}$. alkene). $7.3 \mathrm{l}(2 \mathrm{H} . \mathrm{d}$. thiophene). $7.39(2 \mathrm{H} . \mathrm{d}$ aromatic). $7.83-7.86(3 \mathrm{H} . \mathrm{m}$. aromatic): ${ }^{13} \mathrm{C}$ NMR (100.4 MHz, $\left.\mathrm{CDCl}_{3}\right) .139 .6,139.1,133.4$. 130.5. 129.1, 128.9, 128.1, 127.2, 126.2,116.8, 106.1.

$4-\mathrm{BrC}_{6} \mathrm{H}_{5} \mathrm{CH}=\mathrm{C}(\mathrm{CN}) \mathrm{C}_{4} \mathrm{SH}_{3}:$ m.p. $91-93{ }^{\circ} \mathrm{C}, \lambda_{\text {max }} 340$ nun; IR (KBr), 3027 (C-H, aromatic), $2219(\mathrm{C} \equiv \mathrm{N}) .1585$
$\left(\mathrm{C}=\mathrm{C}\right.$. alkene), $1591\left(\mathrm{C}=\mathrm{C}\right.$. aromatic); ${ }^{1} \mathrm{H} \mathrm{NMR}(400 \mathrm{MHz}$, $\left.\mathrm{CDCl}_{3}\right) .7 .29(\mathrm{lH}, \mathrm{s}$, alkene), 7.31 ( $2 \mathrm{H}$. d, thiophene). 7.39 $(2 \mathrm{H}$. d, thiophene), $7.56(2 \mathrm{H}$. d, aromatic), $7.70(2 \mathrm{H}, \mathrm{d}$, aromatic); ${ }^{13} \mathrm{C}$ NMR (100.4 MHz. $\left.\mathrm{CDCl}_{3}\right)$. 137.9. 132.2, 130.3. 128.2, 127.6. 127.3, 127.1. 126.5. 124.7, 116.5, 106.7.

Kinetic Measurement. The reaction was followed spectrophotometrically by monitoring the decrease in the concentration of $\alpha$-thiophenyl- $\beta$-phenylacylonitriles. [TPA]. at $\lambda_{\text {max }}$ of the substrate to over $80 \%$ completion. The reaction was studied under pseudo-first-order condition. [TPA] = $6.0 \times 10^{-5} \mathrm{M}$ and $[\mathrm{BA}]=3.0-4.5 \times 10^{-1} \mathrm{M}$ at $25.0 \pm 0.1^{\circ} \mathrm{C}$ The pseudo first-order rate constant. $k_{\mathrm{obs}}$, was determined form the slope of the plot $(r>0.994) \ln [\mathrm{TPA}]$ is time. Second-order rate constants. $k \mathrm{v}$, were obtained from the slope of a plot $(\mathrm{r}>0.995)$ of $k_{\mathrm{obs}}$ s $s$. benzylamine with more than six concentrations of more than three runs and were reproducible to within $\pm 3 \%$.

Product Analysis. The analysis of final products was difficult due to partial decomposition during product separation and purification. We therefore analysed the reaction mixture by NMR (IEOL $400 \mathrm{MHz}$ ) at appropriate intervals under exactly the same reaction conditions as the kinetic measurement in $\mathrm{CD}_{3} \mathrm{CN}$ at $25.0^{\circ} \mathrm{C}$. Initially we found a peak for $\mathrm{CH}$ in the reactant. $\mathrm{C}_{6} \mathrm{H}_{5} \mathrm{CH}=\mathrm{C}\left(\mathrm{CN} \mathrm{C}_{4} \mathrm{H}_{3} \mathrm{~S}\right.$ at $7.65 \mathrm{ppm}$, which was gradually reduced. and a new two peaks for $\mathrm{CH}$ $\mathrm{CH}$ in the product, $\mathrm{C}_{4} \mathrm{H}_{5}\left(\mathrm{MeOC} \cdot \mathrm{H}_{4} \mathrm{CH}_{2} \mathrm{NH}\right) \mathrm{CH}-\mathrm{CH}(\mathrm{CN})-$ $\mathrm{C}_{4} \mathrm{H}_{3} \mathrm{~S}$, grew at 4.67 and $5.58 \mathrm{ppm}$ as the reaction proceed No other peaks or complications were found during the reaction except the 3 peak height changes indicating that the reaction proceeds with no other side reactions.

Acknowledgement. This paper was supported by research fund of Chonbuk National University.

\section{References}

1. (a) Oh. H. K: Yang. T. H.: Sung. D. D.: Lee. I. J. Chem. Sax. Perkin Trans. 22000,101 . (b) Oh, H. K.: Yang, J. H. Lee. H. W: Lee. I. J. Org. Chent 2000. 65. 2188 . (c) Oh. H. K.: Yang. I. H.: Lee. H. W: Lee. I. J. Org. Chem 2000. 65, 5391 . (d) Oh, H. K: Yang. J. H. Hwang. Y. H.: Lee. H. W.; Lee. I. Bull Korean Chem. Soc. 2002. 23. 221. (e) Oh. H. K.: Kim. T. S.: Lee. H. W.: Lee. I. J Chem. Soc. Perkin Trans. 2 2002. 282. (f) Oh. H. K.; Kim, I. K: Lee. H. W.: Lee. I. J. Org. Chem. 2004. 69. 3806.

2. (a) Bernasconi. C. F. Tetrahedron 1989. 45.4017. (b) Bernasconi. C. F. Ace. Chent Res. 1987.20.301.

3. (a) Lee. I. Ad: Phs. Ong Chent 1992. 27. 57 (b) Lee. I.: Lee. H W. Coll. Czech Chem. Commm. 1999, 64. 1529. (c) Lee. I Chen. Soc. Rev: 1990. 19.317.

4. (a) Bernasconi, C. F.: Renfrow, R. A. J. Org. Chem 1992, 52. 3035. (b) Bernasconi. C. F.: Murray. C. J.: Fox. T. P.: Carre. D. I. J. Am. Chem. Soc. 1983, 105. 4349 .

5. Hanseh, C.: Leo. A.; Taft. R. W. Chem Rev 1991. 91. 165.

6. Stewart. R.: Kroeger. D. Can. J. Chen 1967. 45.2173.

7. (a) Page. M.: Williams, A. Organic and Bio-organic Mechanisms, Longmant: London. 1977: p 250. (b) Hansch. C.: Hoektnan1. D.: Gao. H. Chem. Rev. 1996. 96, 1045.

8. Lee. I. Chem. Soc. Rev 1995. 24. 223.

9. (a) Oh. H. K: Ku. M. H.: Lee. H. W. Bull Konem Chent Soc 2005. 26. 935. (b) Oh. H. K.: Ku. M. H. Bull. Korean Chem. Soc. 2006. 27. 1873

10. Schonne, A.: Braye. E.: Bruyland. A. Bull. Soc. Chim Belg. 1953. 62. 155. 